\title{
EFFECTS OF NONLINEARITY ON DETERMINATION OF BOLT FORCES FOR THE OPERATIONAL STATE OF A BOLTED FLANGE CONNECTION
}

\author{
R. GRZEJDA \\ Faculty of Mechanical Engineering and Mechatronics \\ West Pomeranian University of Technology \\ Szczecin, POLAND \\ E-mail: rafal.grzejda@zut.edu.pl
}

\begin{abstract}
Modelling and calculations of an asymmetrical bolted flange connection at the operational stage are presented. The physical model of the joint is based on a flexible flange element that is connected with a rigid support by means of hybrid elements, which substitute bolts. Between the flange element and the support, the linear Winkler model of a contact layer is taken into account. The bolted flange connection is preloaded and then subjected to an eccentric normal load. The influence of nonlinearity of the contact layer between the joined elements on computational values of bolt forces has been investigated. Results of calculations for several different values of the joined element's thickness are described.
\end{abstract}

Key words: bolted flange connection, operational state, bolt force.

\section{Introduction}

In general, mechanical characteristics of contact joints are nonlinear (Abdo, 2006; Goerke and Willner, 2008; Gonzalez-Valadez et al., 2010; Kono et al., 2013). In the case of normal loads and deformations, these characteristics can be represented with a good approximation by an exponential function (Grudziński and Kostek, 2007; Kostek, 2013; Misra and Huang, 2011). However, the extent of this function depends on values of loads acting on the connection. Considering the case of the contact joint between the elements joined in a preloaded bolted flange connection, it can be assumed that the normal characteristics of the contact are already close to linear.

There are many models of bolted connections that have been described in the published literature. These can be divided into two groups. The first one deals with modelling of single-bolted joints by means of:

- the well-known Rötscher model of the bolted joint (Witek and Grzejda, 2011), in which the contact layer between the joined elements is not taken into consideration (Agatonović, 2011; Croccolo et al., 2012; Haidar et al., 2011),

- the finite element method - FEM (Abid and Nash, 2003; Al-Nassar et al., 2012; Chakherlou et al., 2012; Chung and Ip, 2000; Iancu et al., 2005), in which for modelling of the contact layer between the joined elements, default contact elements, used in commercial finite element analysis systems, are applied.

In addition, also nonlinear finite contact elements can be implemented to analyze the mechanical contact between the joined elements in single-bolted joints (Żyliński and Buczkowski, 2010).

The models described in this first group of publications usually cannot be directly applied to modelling and calculations of multi-bolted flange connections.

The other group of models are dedicated to modelling of multi-bolted joints. The most popular method adopted in these models is the finite element method. It is used, taking into account the following kind of elements:

- linear contact elements with constant values of the contact stiffness coefficients, commonly available in commercial finite element analysis systems (Gerami et al., 2011; Maggi et al., 2005; Pirmoz, 2011; Pirmoz et al., 2009; Saedi Daryan et al., 2011; Shi et al., 2008; Wang et al., 2013), 
- nonlinear contact elements (Bucher and Ebert, 2002; Girão Coelho, 2013).

Additionally, also the piecewise linear elastic penalty law can be applied to analyze the mechanical contact between the joined elements in multi-bolted joints (Mayer and Gaul, 2007).

These works mostly deal with classical types of symmetrical joints:

- bolted angle connections (Pirmoz, 2011; Pirmoz et al., 2009; Saedi Daryan et al., 2011),

- bolted end-plate connections (Gerami et al., 2011; Girão Coelho, 2013; Maggi et al., 2005; Shi et al., 2008),

- bolted flange connections (Bucher and Ebert, 2002; Mayer and Gaul, 2007; Wang et al., 2013).

In the previous paper of the author (Grzejda, 2013b) some results of theoretical investigations of an asymmetrical preloaded bolted connection of a flange and a rigid support, subjected to an external normal load, were released. In the model of the joint, bolts were treated as hybrid elements and between the flange element and the support, the nonlinear Winkler model of the contact layer was taken into consideration. In the current paper some new results of investigations of an analogical model of the joint are presented. In the new model, the linear Winkler model of the contact layer between the joined elements is taken into account. The model of the bolted flange connection presented in the paper is dedicated to modelling of joints of a flexible flange and a rigid support, but it can be used to design all kinds of arbitrary joints with any arrangement of the bolts. For modelling of the bolted flange connection the finite element method is used.

\section{Physical model of the bolted flange connection}

A general structure of the bolted flange connection model results from an idea presented in Grzejda (2013b). The model of the joint is based on a flexible flange element that is fastened to a rigid support by means of $k$ hybrid elements (Grzejda, 2009), which substitute bolts, preloaded by forces $F_{m i}$ (Fig.1).

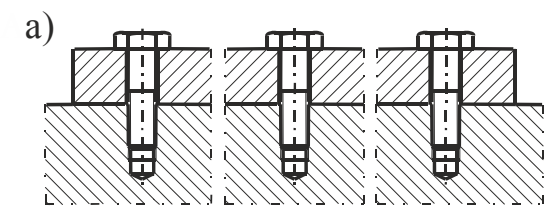

b)

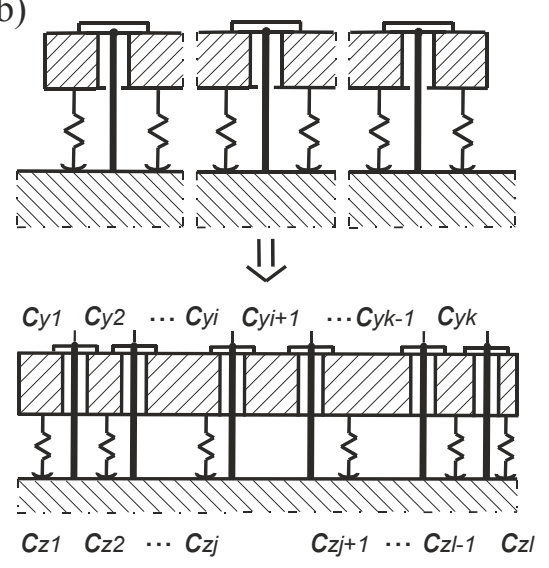

c)

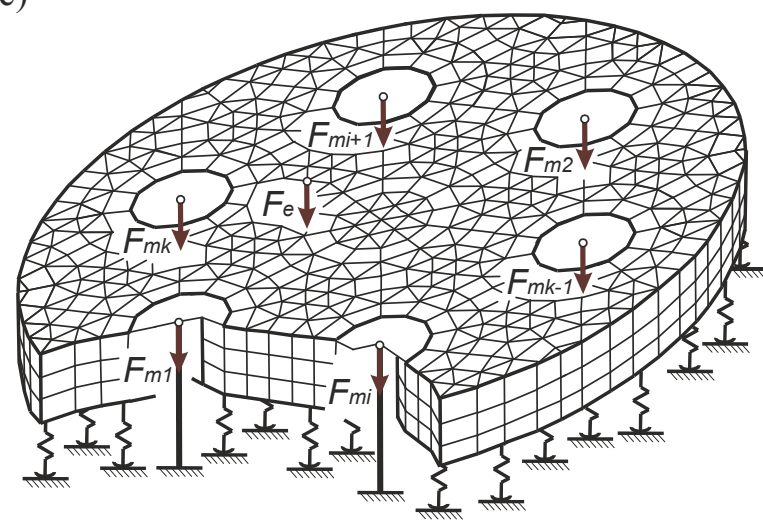

Fig.1. Bolted flange connection: a) diagram of the joint, b) description of system spring properties, c) FEMmodel of the joint.

Spring properties of the $i$-th bolt's model (for $i=1,2, \ldots, k$ ) are determined from the formula

$$
c_{y i}=\frac{1}{e_{y i}}
$$


where $e_{y i}$ is the linear flexibility coefficient of the $i$-th bolt's model, which is calculated as follows

$$
e_{y i}=\sum_{n} e_{n}
$$

where $e_{n}$ denotes the flexibility coefficient of the $n$-th bolt's fragment.

A contact layer between the flange element and the support is modeled as the linear Winkler model, which is described by means of $l$ one-sided linear spring elements, characterized by the following relationship

$$
R_{j}=A_{j} \cdot f\left(u_{j}\right)
$$

where: $R_{j}$ is the force in the centre of the $j$-th elementary contact area, $A_{j}$ is the $j$-th elementary contact area and $u_{j}$ is deformation of the $j$-th linear spring element of the contact layer (for $j=1,2, \ldots, l$ ).

The equation of system equilibrium (Fig.1c.) can be written in the form

$$
\boldsymbol{K} \cdot \boldsymbol{q}=\boldsymbol{p}
$$

where: $\boldsymbol{K}$ is the stiffness matrix, $\boldsymbol{q}$ is the displacements vector and $\boldsymbol{p}$ is the loads vector.

In the operational state, the loads vector $\boldsymbol{p}$ is composed of external normal loads $F_{e}$ (Fig.1c).

The generating procedure of the stiffness matrix $\boldsymbol{K}$ is presented in Witek and Grzejda (2005). Adopting the division of the joint into three subsystems $(\boldsymbol{B}$ - the set of bolts, $\boldsymbol{F}$ - the flange element model, $\boldsymbol{C}$ - the linear Winkler model of the contact layer), Eq.(2.4) can be rewritten as

$$
\left[\begin{array}{ccc}
\boldsymbol{K}_{B B} & \boldsymbol{K}_{B F} & \boldsymbol{0} \\
\boldsymbol{K}_{F B} & \boldsymbol{K}_{F F} & \boldsymbol{K}_{F C} \\
\boldsymbol{0} & \boldsymbol{K}_{C F} & \boldsymbol{K}_{C C}
\end{array}\right] \cdot\left[\begin{array}{l}
\boldsymbol{q}_{B} \\
\boldsymbol{q}_{F} \\
\boldsymbol{q}_{C}
\end{array}\right]=\boldsymbol{p}
$$

where: $\boldsymbol{K}_{B B}, \boldsymbol{K}_{F F}, \boldsymbol{K}_{C C}$ are the stiffness matrices of subsystems $\boldsymbol{B}, \boldsymbol{F}, \boldsymbol{C} ; \boldsymbol{K}_{B F}, \boldsymbol{K}_{F B}, \boldsymbol{K}_{F C}, \boldsymbol{K}_{C F}$ are the matrices of elastic couplings among subsystems $\boldsymbol{B}, \boldsymbol{F}, \boldsymbol{C}$ and $\boldsymbol{q}_{B}, \boldsymbol{q}_{F}, \boldsymbol{q}_{C}$ are the displacements vectors of subsystems $\boldsymbol{B}, \boldsymbol{F}, \boldsymbol{C}$.

On the grounds of so defined model of the bolted flange connection, displacements of bolts and bolt forces after the operational state has been completed can be evaluated.

a)

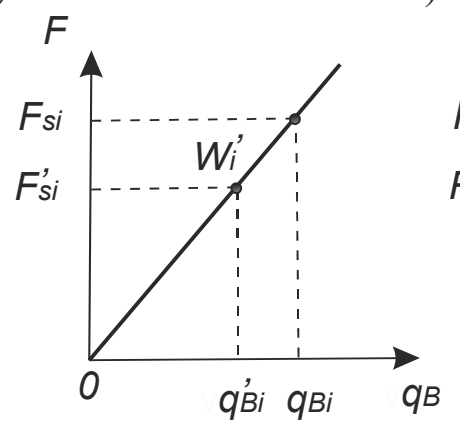

b)

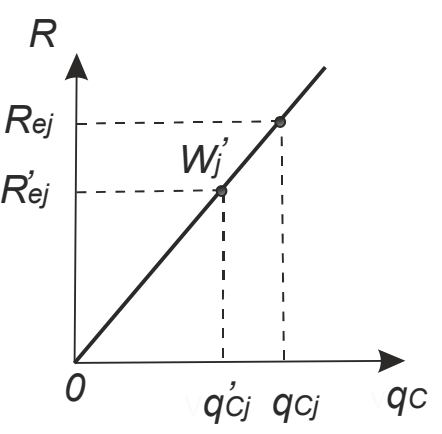

Fig.2. Determination of the working load: a) in the case of linear hybrid elements, which substitute bolts, b) in the case of linear springs, which are elements of the contact layer. 
A starting point for calculations of the bolted flange connection at the operational stage are the data obtained at the end of its assembly operation (Grzejda, 2013a). As a result of solving Eq.(2.5) one obtains the displacements vector of bolts $\boldsymbol{q}_{B}$

$$
\boldsymbol{q}_{B}=\operatorname{col}\left(q_{B 1}, q_{B 2}, \ldots, q_{B i}, \ldots, q_{B k}\right) .
$$

Final displacements of bolts $q_{B i}$ are measured from the working points $W_{i}^{\prime}$, which determine tension of bolts in the previous step of calculations (Fig.2a.). On the basis of so defined displacements $q_{B i}$, forces in bolts $F_{s i}$ can be computed using the formula

$$
F_{s i}=c_{y i} \cdot q_{B i} .
$$

As a result of solving Eq.(2.5) one obtains the displacements vector of linear springs $\boldsymbol{q}_{C}$ too, which can be evaluated from the relation

$$
\boldsymbol{q}_{C}=\operatorname{col}\left(q_{C 1}, q_{C 2}, \ldots, q_{C j}, \ldots, q_{C l}\right)
$$

Final displacements of elements of the contact layer $q_{C j}$ are measured from the working points $W_{j}^{\prime}$, which determine their tension in the previous step of calculations (Fig.2b). On the basis of so defined displacements $q_{C j}$, forces in the contact layer $R_{e j}$ can be computed from Eq.(2.3) for $u_{j}$ equal to $q_{C j}$.

The diagram of iterative calculations of the bolted flange connection is shown in Fig.3.

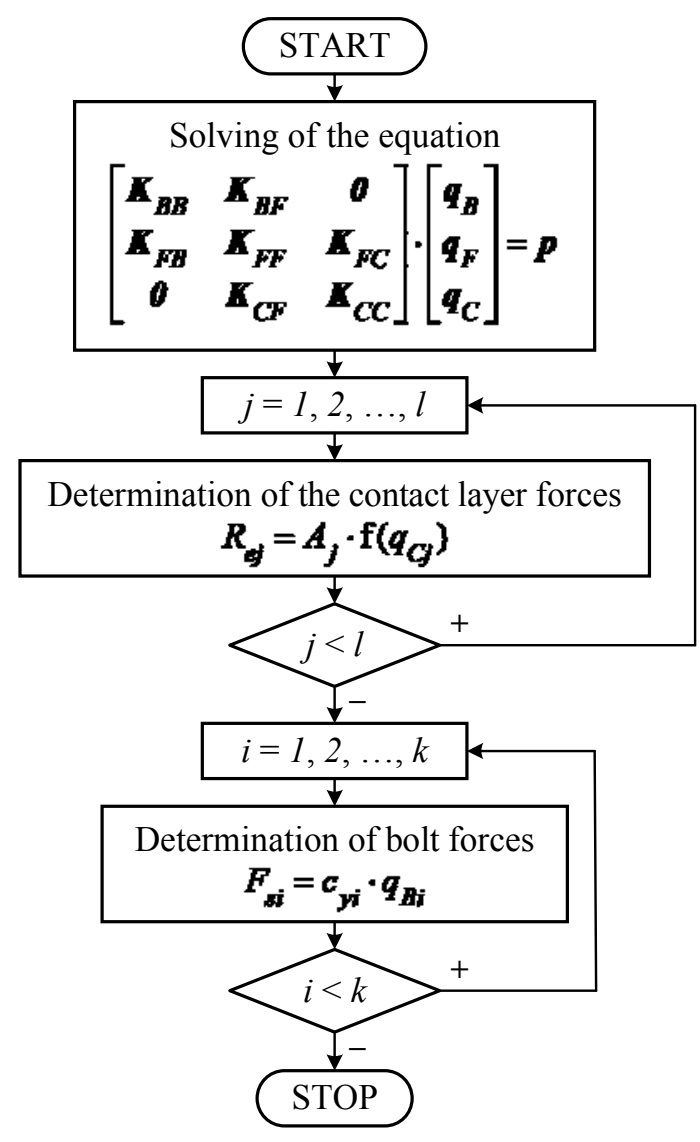

Fig.3. Scheme of iterative calculations of the bolted flange connection. 


\section{Calculations of the bolted flange connection at the operational stage}

According to the proposed method, computations of an asymmetrical 7-bolted flange connection were performed. A simplified FEM-based model of the joined element is shown in Fig.4a.

a)

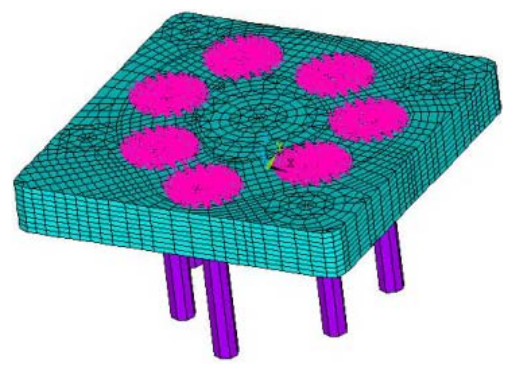

b)

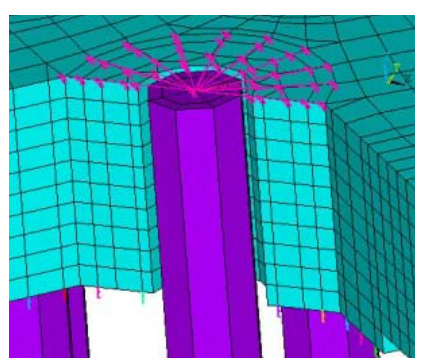

c)

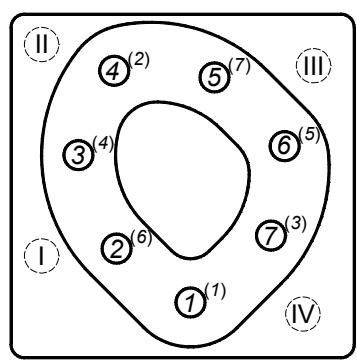

Fig.4. Assumed bolted flange connection: a) simplified FEM-based model, b) fragment of the crosssection, c) contact surface.

a)
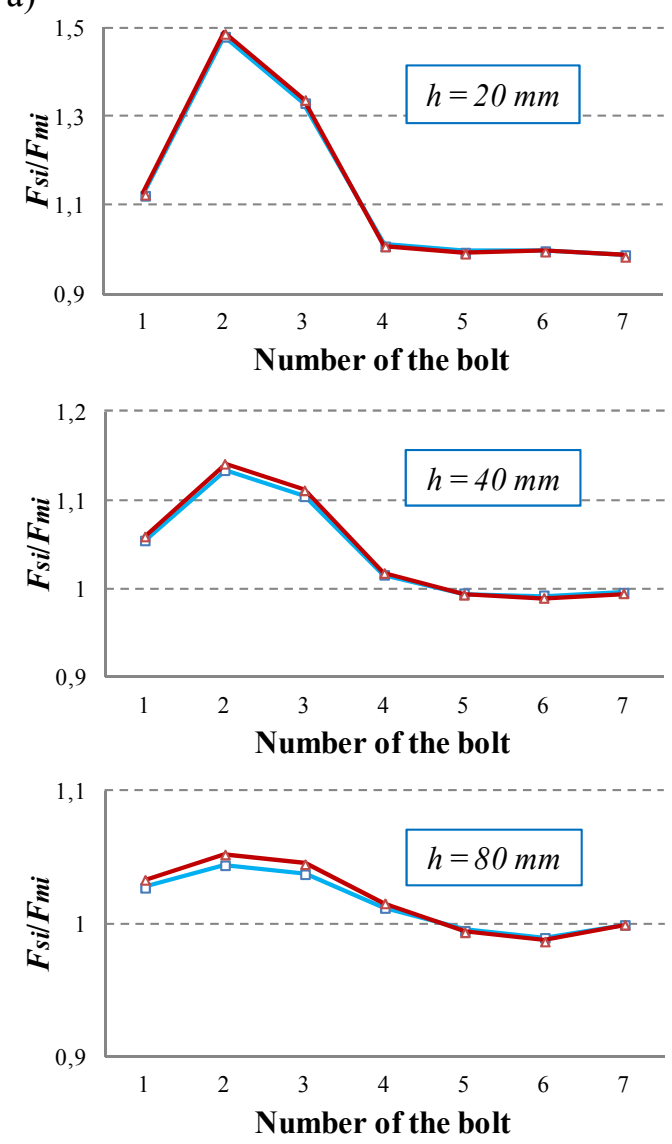

b)
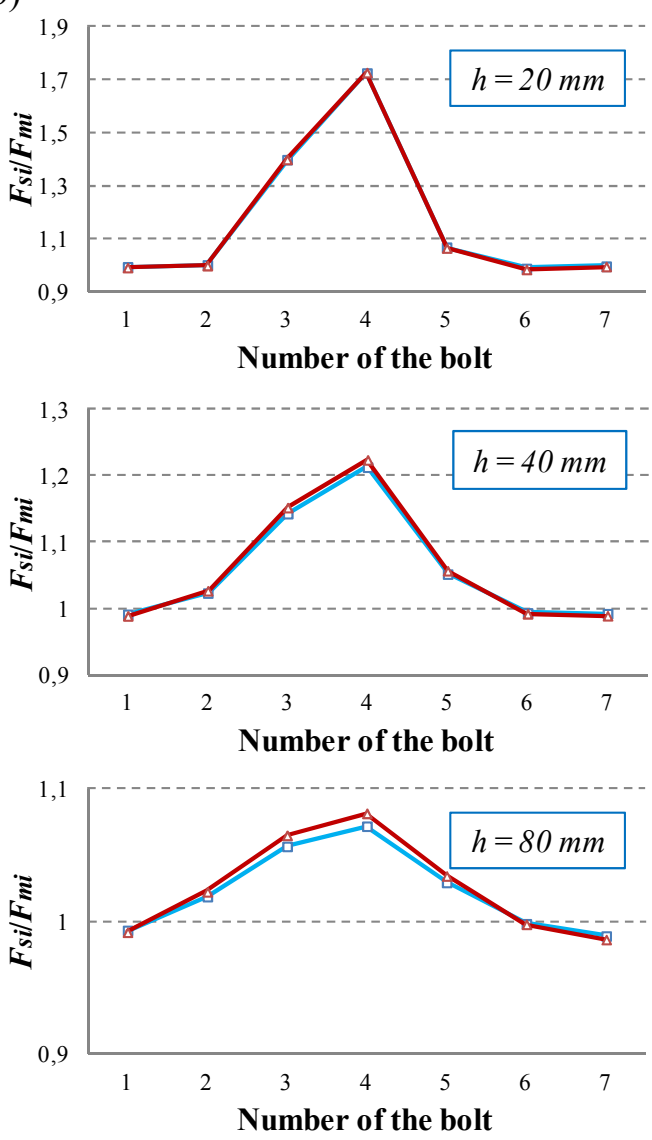

$-\square-L-N L$

Fig.5. Bolt load values in the joint loaded externally at the point: a) I, b) II. 
A fragment of the cross-section of the joint with models of bolts and the contact layer is illustrated in Fig.4b. A contact surface between the joined elements as well as the bolt's arrangement and their numeration are shown in Fig.4c. Calculations were carried out for three values of the joined element's thickness $h$ (for $h \in\{20 \mathrm{~mm}, 40 \mathrm{~mm}, 80 \mathrm{~mm}\})$. Characteristics of linear contact springs are described as the following function (Grzejda, 2009)

$$
R_{j}=A_{j} \cdot\left(26.873 \cdot u_{j}\right) .
$$

To fastening of the joint, the bolts $M 10 \times 1.25$ are used. The standard preload of bolts $F_{m i}$ is equal to $20 \mathrm{kN}$. The tightening sequence taken here according to Grzejda (2009), is parenthesized in Fig.4c. After the preloading process, the bolted flange connection is subjected to an eccentric normal load $F_{e}$ equal to $50 \mathrm{kN}$ acting consecutively at four points (I, II, III, IV) shown in Fig.4c.

a)
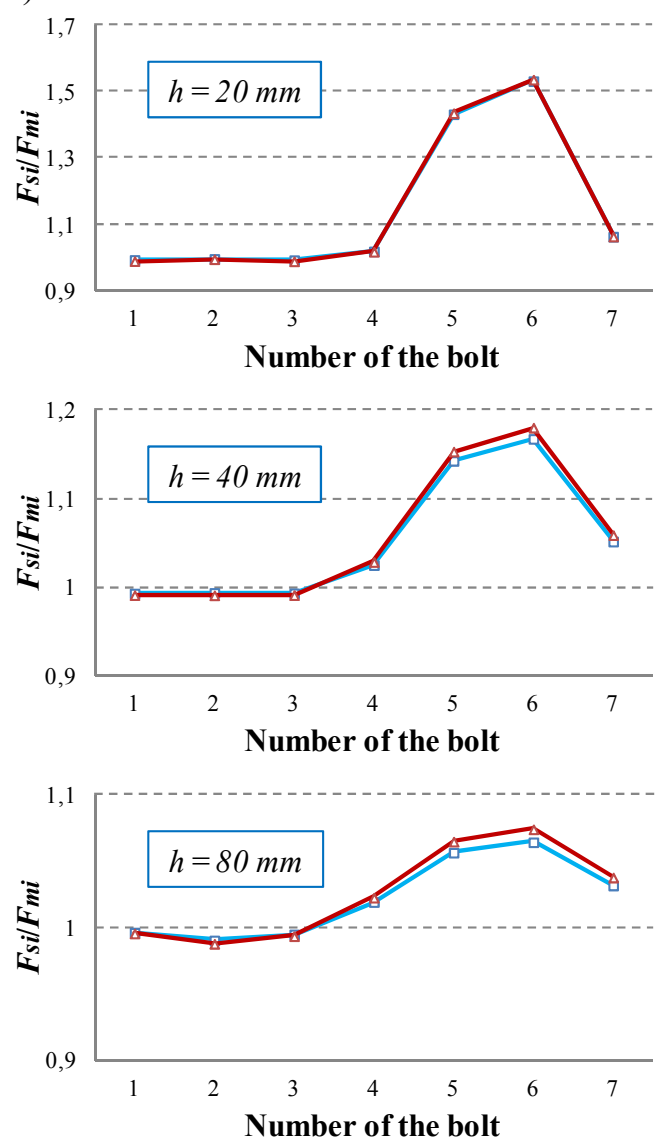

b)
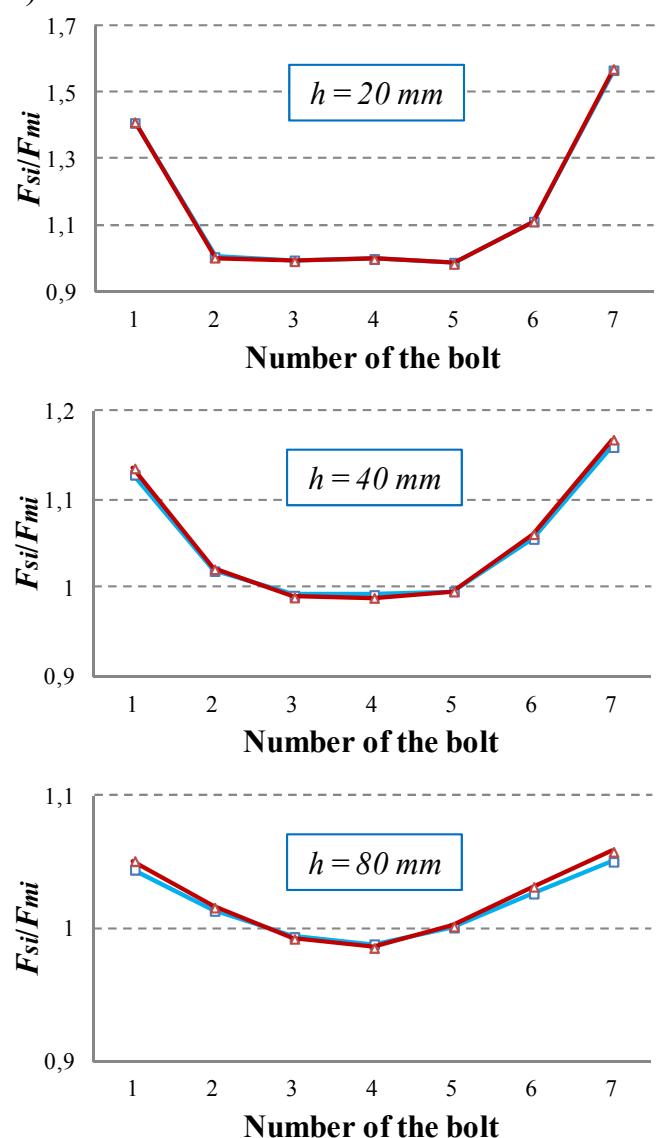

$\neg-L \neg-N L$

Fig.6. Bolt load values in the joint loaded externally at the point: a) III, b) IV.

Results of calculations were put together in graphs illustrated in Figs 5-6 according to both the individual thickness of the flange element $h$ and four points of the load $F_{e}$ acting. In the respective figures, values of bolt forces $F_{s i}$ related to preloads $F_{m i}$ (Grzejda, 2013a) are presented. For describing the results of calculations the following nomenclature is introduced: 
- the $L$-model - the model of the joint with the linear Winkler model of the contact layer,

- the $N L$-model - the model of the joint with the nonlinear Winkler model of the contact layer (Grzejda, 2013b).

In most of the cases, values of forces in individual bolts computed according to the $L$-model of the joint are smaller than their values obtained according to the $N L$-model of the joint. The relative difference between the obtained bolts forces is analyzed on the basis of the $W$ index

$$
W=\left|\frac{F_{s \max }^{L}-F_{s \max }^{N L}}{F_{s \max }^{N L}}\right| \cdot 100 \%
$$

where: $F_{s \max }^{L}$ is the maximal force in bolts according to the $L$-model of the joint and $F_{s}^{N L a x}$ is the maximal force in bolts according to the $N L$-model of the joint.

Table 1. $W$ index values as a function of the joined element's thickness.

\begin{tabular}{|c|c|c|c|}
\cline { 2 - 4 } \multicolumn{1}{c|}{} & $h=20 \mathrm{~mm}$ & $h=40 \mathrm{~mm}$ & $h=80 \mathrm{~mm}$ \\
\hline \multirow{3}{*}{} & \multicolumn{3}{|c|}{ Point No. I } \\
\cline { 2 - 4 } & 0.52 & 0.64 & 0.76 \\
\cline { 2 - 4 } & \multicolumn{3}{|c|}{ Point No. II } \\
\cline { 2 - 4 } & 0.10 & 0.90 & 0.90 \\
\cline { 2 - 4 } & \multicolumn{3}{|c|}{ Point No. III } \\
\cline { 2 - 4 } & 0.30 & Point No. IV \\
\cline { 2 - 4 } & \multicolumn{3}{|c|}{0.73} \\
\hline
\end{tabular}

$W$ index values as a function of the thickness of the joined element are set up in Tab.1. On the grounds of comparisons, it can be noted that the accuracy of calculation results by means of the linear bolted flange connection model generally decreases with a reduction of joined element's flexibility. Depending on the joined element's thickness, the error of estimation may change up to $1.07 \%$.

\section{Conclusions}

In the case of bolted flange connections preloaded pursuant to technical standards (Hövel and Hecker, 2003) and then subjected to an eccentric normal load, nonlinearity of the contact layer between the joined elements has a negligible influence on computational values of bolt forces. It is associated with initial clamping of the joined elements at the end of the assembly process, during which elements' surface roughness is highly reduced. Wherefore for calculations and analysis of such joints, the linear Winkler model of the contact layer can be applied. Owing to this fact, one achieves significantly higher efficiency of modelling, which is brought on by both the smaller complexity of the problem and considerably shorter process time.

In the paper, a system approach to modelling of bolted flange connections is presented. The scope of application of the method can be easily extended. This is possible by modifying individual subsystems $\boldsymbol{B}, \boldsymbol{F}$, $\boldsymbol{C}$ or by adding next subsystems to the bolted system (for instance a flexible support). The effects of work on this subject will be published in future articles. 


\section{Nomenclature}

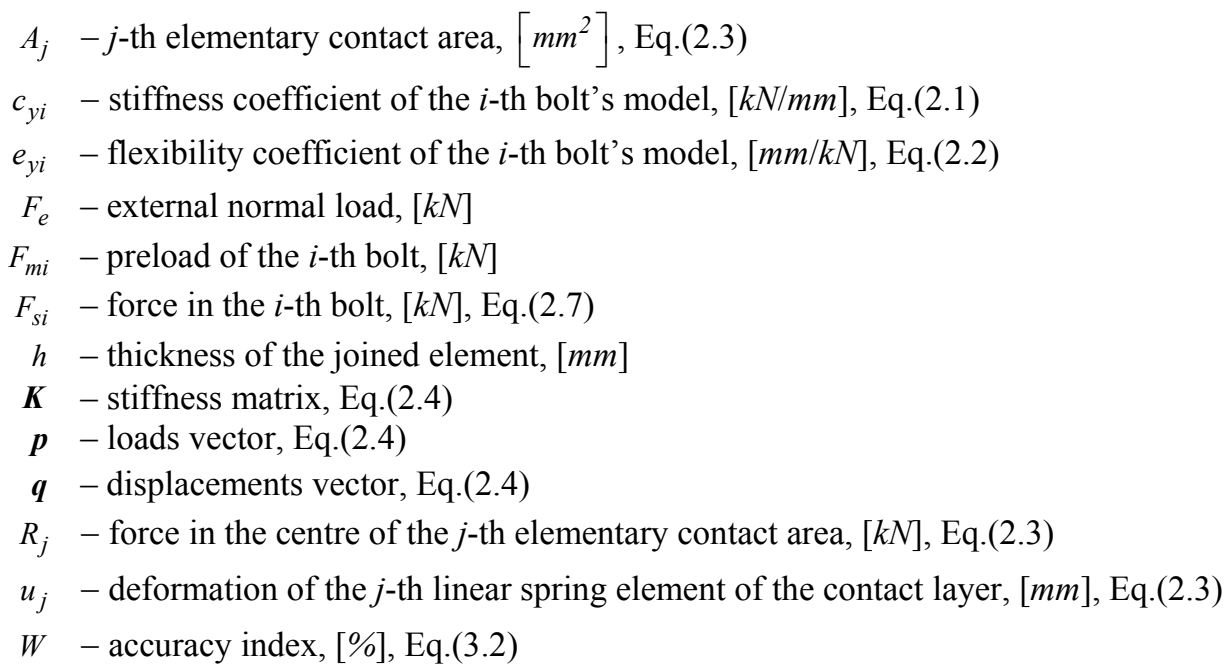

\section{Superscripts}

$L$ - linear model of the bolted flange connection

$N L$ - nonlinear model of the bolted flange connection

\section{Subscripts}

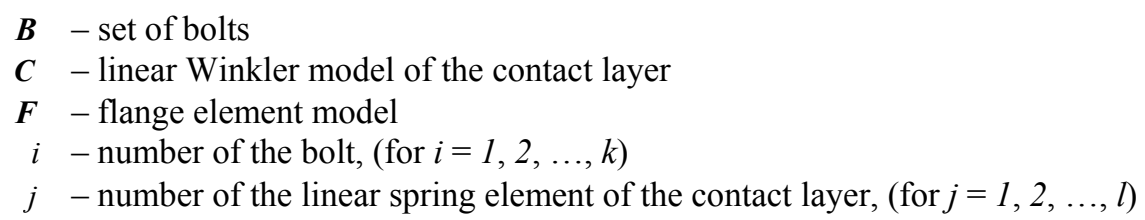

\section{References}

Abdo J. (2006): Modeling of frictional contact parameters of mechanical systems. - International Journal of Applied Mechanics and Engineering, vol.11, No.3, pp.449-465.

Abid M. and Nash D.H. (2003): Comparative study of the behaviour of conventional gasketed and compact non-gasketed flanged pipe joints under bolt up and operating conditions. - International Journal of Pressure Vessels and Piping, vol.80, No.12, pp.831-841.

Agatonović P. (2011): Structural integrity analysis of multi-bolted connections using the innovative beam model. Structural Integrity and Life, vol.11, No.3, pp.147-156.

Al-Nassar Y.N., Khurshid H. and Arif A.F.M. (2012): The effect of clearance and pre-tension on the performance of a bolted-joint using 3D FEA. - Arabian Journal for Science and Engineering, vol.37, No.3, pp.749-763.

Bucher Ch. and Ebert M. (2002): Nonlinear calculation of steel flange connections with measured imperfections (in German). - Stahlbau, vol.71, No.7, pp.516-522.

Chakherlou T.N., Razavi M.J. and Aghdam A.B. (2012): On the variation of clamping force in bolted double lap joints subjected to longitudinal loading: A numerical and experimental investigation. - Strain, vol.48, No.1, pp.21-29.

Chung K.F. and Ip K.H. (2000): Finite element modeling of bolted connections between cold-formed steel strips and hot rolled steel plates under static shear loading. - Engineering Structures, vol.22, No.10, pp.1271-1284. 
Croccolo D., De Agostinis M. and Vincenzi N. (2012): A contribution to the selection and calculation of screws in high duty bolted joints. - International Journal of Pressure Vessels and Piping, vol.96-97, pp.38-48.

Gerami M., Saberi H., Saberi V. and Saedi Daryan A. (2011): Cyclic behavior of bolted connections with different arrangement of bolts. - Journal of Constructional Steel Research, vol.67, No.4, pp.690-705.

Girão Coelho A.M. (2013): Rotation capacity of partial strength steel joints with three-dimensional finite element approach. - Computers and Structures, vol.116, pp.88-97.

Goerke D. and Willner K. (2008): Normal contact of fractal surfaces - Experimental and numerical investigations. Wear, vol.264, No.7-8, pp.589-598.

Gonzalez-Valadez M., Baltazar A. and Dwyer-Joyce R.S. (2010): Study of interfacial stiffness ratio of a rough surface in contact using a spring model. - Wear, vol.268, No.3-4, pp.373-379.

Grudziński K. and Kostek R. (2007): An analysis of nonlinear normal contact microvibrations excited by a harmonic force. - Nonlinear Dynamics, vol.50, No.4, pp.809-815.

Grzejda R. (2009): Modelling and analysis of a multi-bolted joint of a flange element fastened to a nonlinear spring layer (in Polish). - Ph.D. Thesis, Szczecin: West Pomeranian University of Technology, Szczecin.

Grzejda R. (2013a): Determination of bolt forces for the assembly condition of a bolted flange connection. - Archives of Mechanical Technology and Automation, vol.33, No.2, (in Press).

Grzejda R. (2013b): Determination of bolt forces for the operational state of a bolted flange connection. - Advances in Manufacturing Science and Technology, vol.37, No.3, pp.73-83.

Haidar N., Obeed S. and Jawad M. (2011): Mathematical representation of bolted-joint stiffness: A new suggested model. - Journal of Mechanical Science and Technology, vol.25, No.11, pp.2827-2834.

Hövel A. and Hecker P. (2003): Standardization related to the pressure equipment directive with a focus on bolted joints. - Proc. of the 2003 ASME Pressure Vessels and Piping Conference, Analysis of bolted joints. Cleveland: ASME, pp.119-124.

Iancu F., Ding X., Cloud G.L. and Raju B.B. (2005): Three-dimensional investigation of thick single-lap bolted joints. Experimental Mechanics, vol.45, No.4, pp.351-358.

Kono D., Inagaki T., Matsubara A. and Yamaji I. (2013): Stiffness model of machine tool supports using contact stiffness. - Precision Engineering, vol.37, No.3, pp.650-657.

Kostek R. (2013): An analysis of the primary and superharmonic contact resonances - Part 2. - Journal of Theoretical and Applied Mechanics, vol.51, No.3, pp.687-696.

Maggi Y.I., Gonçalves R.M., Leon R.T. and Ribeiro L.F.L. (2005): Parametric analysis of steel bolted end plate connections using finite element modeling. - Journal of Constructional Steel Research, vol.61, No.5, pp.689-708.

Mayer M.H. and Gaul L. (2007): Segment-to-segment contact elements for modelling joint interfaces in finite element analysis. - Mechanical Systems and Signal Processing, vol.21, No.2, pp.724-734.

Misra A. and Huang S. (2011): Effect of loading induced anisotropy on the shear behavior of rough interfaces. Tribology International, vol.44, No.5, pp.627-634.

Pirmoz A. (2011): Performance of bolted angle connections in progressive collapse of steel frames. - The Structural Design of Tall and Special Buildings, vol.20, No.3, pp.349-370.

Pirmoz A., Seyed Khoei A., Mohammadrezapour E. and Saedi Daryan A. (2009): Moment-rotation behavior of bolted top-seat angle connections. - Journal of Constructional Steel Research, vol.65, No.4, pp.973-984.

Saedi Daryan A., Ziaei M. and Amirodin Sadrnejad S. (2011): The behavior of top and seat bolted angle connections under blast loading. - Journal of Constructional Steel Research, vol.67, No.10, pp.1463-1474.

Shi G., Shi Y., Wang Y. and Bradford M.A. (2008): Numerical simulation of steel pretensioned bolted end-plate connections of different types and details. - Engineering Structures, vol.30, No.10, pp.2677-2686.

Wang Y.Q., Zong L. and Shi Y.J. (2013): Bending behavior and design model of bolted flange-plate connection. Journal of Constructional Steel Research, vol.84, pp.1-16. 
Witek A. and Grzejda R. (2005): Analysis of a nonlinear multi-bolted joint loaded by a normal force. - Archives of Mechanical Technology and Automation, vol.25, No.2, pp.211-219.

Witek A. and Grzejda R. (2011): Effect of a modelling method of the bolted joint on the bolt force (in Polish). Fundamentals of Machine Design, Directions for Research and Development, Gdańsk: Gdańsk University of Technology, vol.1/3, pp.101-109.

Żyliński B. and Buczkowski R. (2010): Analysis of bolt joint using the finite element method. - The Archive of Mechanical Engineering, vol.57, No.3, pp.275-292.

Received: August 5, 2013

Revised: August 16, 2013 